\title{
Análise da adequabilidade de indicadores de erodibilidade de solos baseados em parâmetros geotécnicos
}

Os processos erosivos são capazes de causar mudanças no cenário em que atuam, causando prejuízos materiais e fatalidades. Esse estudo tem papel importante pois pode auxiliar na previsão do comportamento do solo, e mapeamento das áreas de risco com maior precisão, evitando que pessoas se estabeleçam nessas áreas. Uma voçoroca foi selecionada na Avenida Litorânea, São Luís (MA). Três amostras foram colhidas em diferentes níveis (0m, $1.5 \mathrm{~m}, 3 \mathrm{~m}$ ) para realização de ensaios de granulometria, teor de umidade, limite de liquidez e limite de plasticidade. A literatura apresenta propostas que relacionam os índices físicos do solo e a susceptibilidade do mesmo a sofrer erosão. Fazendo essa correlação, os resultados encontrados apontam que alguns critérios previram bem o comportamento do solo enquanto outros fizeram previsões incorretas. Pela ausência de um banco de dados amplo, e pela análise de adequabilidade ainda estar acontecendo, fazer uso desses métodos requer muito cuidado.

Palavras-chave: Análise de Adequabilidade; Erosão; Erodibilidade; Solo; Parâmetros Geotécnicos.

\section{Analysis of the suitability of soil erodibility indicators based on geotechnical parameters}

\begin{abstract}
Erosive processes are capable of causing changes in the scenario in which they operate, causing material losses and fatalities. This study has an important role since it can help in predicting soil behavior, and mapping areas of risk with greater precision, preventing people from establishing themselves in those areas. A gully was selected in the Litorânea Avenue, São Luís (MA). Three samples were collected at different levels $(0 \mathrm{~m}, 1.5 \mathrm{~m}, 3 \mathrm{~m})$ to perform grain size, moisture content, liquidity limit and plasticity limits. The literature presents proposals that relate the soil physical indexes and the soil susceptibility to erosion. By making this correlation, the results found that some criteria predicted well the behavior of the soil while others made incorrect predictions. Because of the absence of a database, and the adequacy analysis is still going on, making use of these methods requires great care.
\end{abstract}

Keywords: Adequacy Analysis; Erosion; Soil; Erodibility; Geotechnical Parameters.

Topic: Geodésia, Cartografia e Sensoriamento Remoto

Reviewed anonymously in the process of blind peer.

Ramon Eduardo Salles dos Santos

Universidade Federal do Maranhão, Brasil

http://lattes.cnpq.br/7579311278105866

http://orcid.org/0000-0003-1058-8437

ramoneduardosalles@gmail.com

Rodrigo da Cruz de Araujo

Universidade Federal do Maranhão, Brasil

http://lattes.cnpq.br/2600077439764627

rodrigocruzaraujo@gmail.com
Received: 14/12/2017

Approved: 24/01/2018
Referencing this:

SANTOS, R. E. S.; ARAUJO, R. C.. Análise da adequabilidade de indicadores de erodibilidade de solos baseados em parâmetros geotécnicos. Revista Ibero Americana de Ciências Ambientais, v.9, n.2, p.115-126, 2018. DOI: http://doi.org/10.6008/CBPC21796858.2018.002.0011

DOI: 10.6008/CBPC2179-6858.2018.002.0011 


\section{INTRODUÇÃO}

Segundo Bertoni et al. (2008), o solo é um recurso básico para os seres vivos, pois suporta toda a cobertura vegetal, e nesta cobertura, está incluso também o homem e sua cultura. O solo é fundamental ao desenvolvimento de diversas atividades humanas, serve de matéria prima para diversas construções, é imprescindível para as atividades agrícolas em larga escala, pois, além de servir de suporte às plantas, fornece nutrientes e água para o seu desenvolvimento e para consumo humano.

A erosão é um processo de deslocamento de terra ou de rochas de uma superfície. Esse processo ocorre por ação de fenômenos da natureza e é intensificado pela ação do ser humano, através da supressão da vegetação e uso e ocupação incorreta do solo. Define-se erosão como sendo a remoção de partículas da crosta terrestre, causada por um ou vários fatores de natureza física, química ou biológica, que tem como característica o modelamento do relevo terrestre (ABNT, 1995). Segundo Bertoni et al. (2008) "Erosão é o processo de desprendimento e arraste acelerado das partículas do solo causado pela água e pelo vento. A erosão do solo constitui, sem dúvida, a principal causa do depauperamento acelerado das terras". A erosão dos solos em áreas urbanas, geralmente em áreas periféricas com solo descoberto, acarretando grandes prejuízos materiais e, por vezes, com perdas de vidas humanas (GUERRA, 2011), resultado do crescimento urbano rápido e desordenado, ocupando o solo sem critérios técnicos que levam em consideração a dinâmica natural do local, principalmente no caso das encostas.

No quesito natureza do solo, a erosão não é igual para todos os solos. As propriedades físicas como a estrutura, textura, permeabilidade e densidade, assim como as características químicas e biológicas exercem influência na erodibilidade do solo. "Suas condições físicas e químicas, ao conferir maior ou menor resistência à ação das águas, tipificam o comportamento de cada solo exposto a condições semelhantes de topografia, chuva e cobertura vegetal" (BERTONI et al., 2008). As propriedades do solo como textura, porosidade, estrutura, permeabilidade, características químicas dentre outras, podem, portanto, influenciar na maior ou menor susceptibilidade aos processos erosivos. O conhecimento dessas características é imprescindível para trabalhos de manejo do solo e controle da erosão (BERTONI et al., 2008). Por esses motivos, o estudo dos diversos fatores condicionantes do solo é uma importante ferramenta para tomar a decisão mais racional e que melhor se encaixa em situações específicas, balanceando o uso do solo, suas características, e como o meio ambiente e o ser humano contribuem para a mudança das características daquele solo, para assim evitar perdas materiais e fatalidades.

O objetivo desse trabalho é estudar a eficácia de critérios de avaliação de erodibilidade que se baseiam em características geotécnicos dos solos, utilizando como parâmetro de referência para tal verificação uma voçoroca em São Luís, Maranhão. Assim, a partir de estudos de laboratório de amostras do solo da referida voçoroca, faz-se uma análise dos resultados obtidos por meio de propostas de correlações entre os parâmetros geotécnicos e a erodibilidade de solos encontradas na literatura, buscando-se, assim, avaliar quais métodos conseguem prever o comportamento erodível do solo com maior precisão. 


\section{METODOLOGIA}

\section{Correlação entre erodibilidade e propriedades geotécnicas do solo}

Ao longo dos anos, várias propostas para avaliação do potencial erosivo dos solos foram desenvolvidas, muitas vezes por meio de correlações com parâmetros do solo como, por exemplo, sua granulometria, limites de consistência, sucção, gênese, capacidade de sorção, etc. No presente trabalho, selecionaram-se alguns desses métodos, que são apresentados a seguir, os quais serão posteriormente utilizados para comparação com as observações de campo da voçoroca ora estudada.

\section{Araújo (2000)}

A primeira proposta leva em consideração o triângulo textural, e uma divisão de duas zonas, indicando a zona com maior suscetibilidade à processos erosivos, e a outra com menor probabilidade deste processo acontecer (Figura 1). Foi proposta por Araújo (2000) a partir da comparação do seu estudo com solos estudados na literatura (FÁCIO, 1991; FONSECA et al., 1981; LIMA, 1999; SANTOS, 1997).

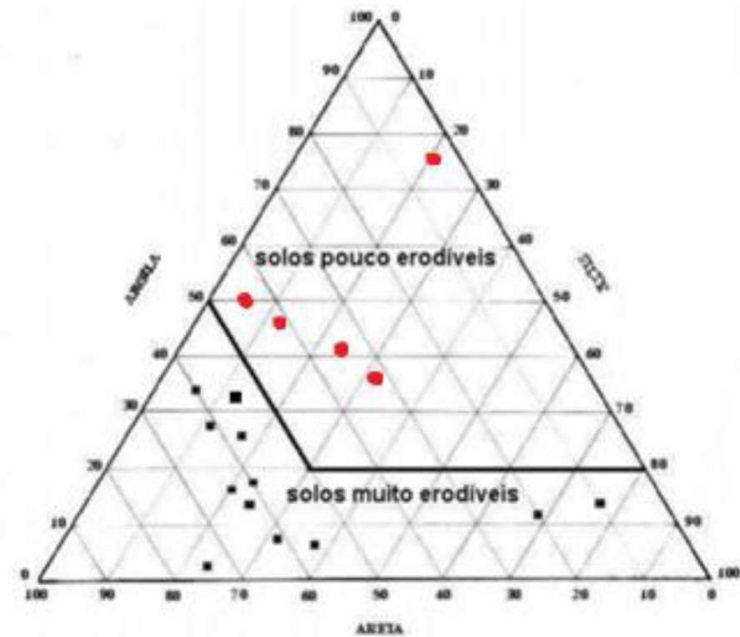

- Solos muito erodiveis (Fonseca e Ferreira, 1981; Fácio, 1991; Santos, 1997; Lima, 1999, Araujo, 2000) Solos pouco erodiveis (Fonseca e Ferreira, 1981; Fácio, 1991; Santos, 1997; Lima, 1999, Araujo, 2000)

Figura 1: Triangulo Textural proposto por Araújo.

Mannigel et al. (2002)

Mannigel et al. (2002) classificaram os valores do fator erodibilidade do solo (K) nas seguintes classes: a) baixo: com valores entre 0,01 e 0,03 t.ha.h/ha.MJ.mm; b) médio: com valores entre 0,03 e 0,06 t.ha.h/ha.MJ.mm, e c) alto: com valores acima de 0,06 t.ha.h/ha.MJ.mm. Os valores do fator de erodibilidade (K) são obtidos através da equação a seguir:

$$
\mathrm{K}=\left(\frac{\% \text { AREIA }+\% \text { SILTE }}{\% \text { ARGILA }}\right) / 100
$$

\section{Santos (1953); Santos et al. (1967)}

Santos (1953) e Santos et al. (1967) classificam o solo como tendo ou não um bom comportamento contra a erodibilidade de acordo com os critérios a seguir: 


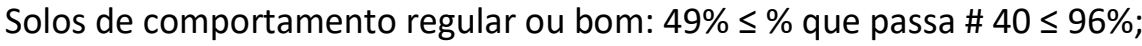

Ou: $0,52<a<0,92 ;$ onde

$$
\mathrm{a}=\frac{\sum \mathrm{Y}}{100 \mathrm{n}}
$$

Sendo:

$Y=$ porcentagem de grãos que passam nas peneiras 7, 14, 25, 50, 100, 200 (ou correspondentes);

$\mathrm{n}$ = número de peneiras (seis).

\section{Gray et al. (1989)}

O Sistema Unificado de Classificação dos Solos foi proposto por Arthur Casagrande no início da década de 40. É um sistema que classifica o solo considerando a granulometria e os limites de liquidez (LL) e de Plasticidade (LP). Utilizando como parâmetro a classificação do SUCS, Gray et al. (1989) classificam a susceptibilidade a erosão de cada tipo de solo, em ordem decrescente da esquerda para a direita, desta maneira:

$$
\mathrm{ML}>\mathrm{SM}>\mathrm{SC}>\mathrm{MH}>\mathrm{OL}>\mathrm{CL}>\mathrm{CH}>\mathrm{GM}>\mathrm{SW}>\mathrm{GP}>\mathrm{GW}
$$

\section{Santos et al. (1967)}

Santos et al. (1967) também desenvolveram estudos com intuito de encontrar possíveis correlações entre a erodibilidade de um solo e suas propriedades. Dentre essas propriedades estudadas, as que os autores consideram mais significativas são o limite de liquidez (LL), limite de plasticidade (LP) e o índice de plasticidade (IP). Para estes, os autores definiram:

Solos de comportamento bom ou regular:

$\mathrm{LP} \leq 32$

IP $\leq 17$

\section{Meireles (1967)}

Meireles (1967) afirma que solos fortemente erodíveis apresentam os seguintes comportamentos: Fortemente erodiveis: $\mathrm{LL} \leq 21 \%$ e IP $\leq 8 \%$ e $\%$ passa \#200 $\leq 20 \%$; Passíveis de forte erosão: $20 \%<\%$ passa $\# 200$ < 40\%; Pouco erodíveis: \% passa \#200 > 40\%.

\section{Santos et al. (2001)}

A última proposta outra proposta para avaliar a erodibilidade dos solos relaciona índice de plasticidade (IP) e Coeficiente de Uniformidade (Cu), conforme Tabela 1. Inicialmente, foi realizada uma etapa de campo, na qual foi selecionada a voçoroca, a ser utilizada como referência de campo para comparação entre o comportamento do material e as previsões obtidas por critérios de avaliação de erodibilidade apresentados na literatura. Nesse contexto, foram coletadas três amostras: uma da parte 
inferior, denominada corpo da voçoroca; outra a 1,5m da cabeceira ou topo da voçoroca; e a terceira, que foi retirada da cabeceira, a cerca de $3 \mathrm{~m}$ do corpo (Figura 2).

Tabela 1: Critérios de Santos et al. (2001).

\begin{tabular}{|l|l|l|l|}
\hline IP & Resistência a Erosão & $\mathrm{Cu}$ & Resistência a Erosão \\
\hline $\mathrm{IP}<6$ & Baixa & $\mathrm{Cu}<5$ & Baixa \\
\hline $15>\mid \mathrm{P}>6$ & Média & $15>\mathrm{Cu}>5$ & Média \\
\hline $\mathrm{IP}>15$ & Alta & $\mathrm{Cu}>15$ & Alta \\
\hline
\end{tabular}

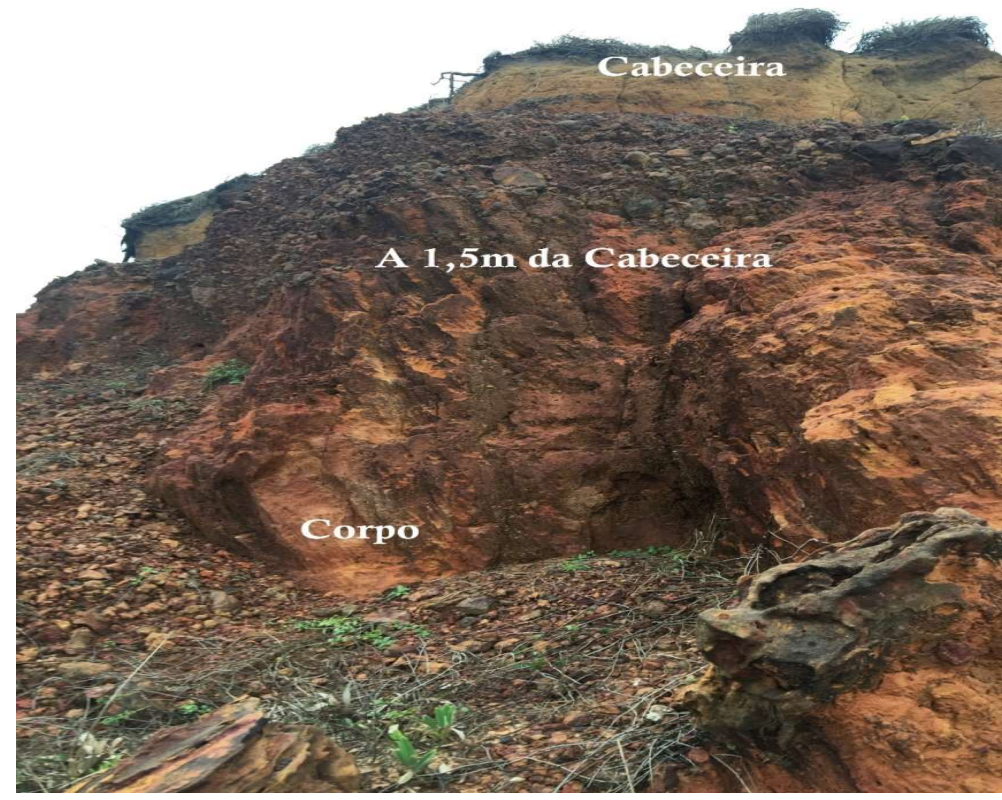

Figura 2: Voçoroca.

Tais amostras foram coletadas para a execução dos ensaios básicos de caracterização do solo, sendo eles: granulometria (peneiramento), umidade (estufa), limite de liquidez (Aparelho de Casagrande) e limite de plasticidade. Os ensaios que foram realizados seguiram as Normas Brasileiras de Regulamentação para haver uma padronização dos resultados, sendo as NBRs: 6457 (Amostras de Solo - Preparação para Ensaios de Compactação e Ensaios de Caracterização) (ABNT, 2016a), 6459 (Solo - Determinação do limite de liquidez) (ABNT, 2016b), 7180 (Solo - Determinação do limite de plasticidade) (ABNT, 2016c) e 7181 (Solo - Análise Granulométrica) (ABNT, 2016d).

\section{Descrição do local}

A voçoroca estudada encontra-se próxima à Av. Litorânea, com coordenadas geográficas 02²9'19,3"S 44¹6'56"W, no município de São Luís, Maranhão. O local está a cerca de 1 km de distância da Praça do Pescador, sentido Ponta D’areia - Olho D'água. Na figura 3 pode-se observar a vista aérea obtida através do Google Earth, onde a região erodida está sinalizada com um losango amarelo. 


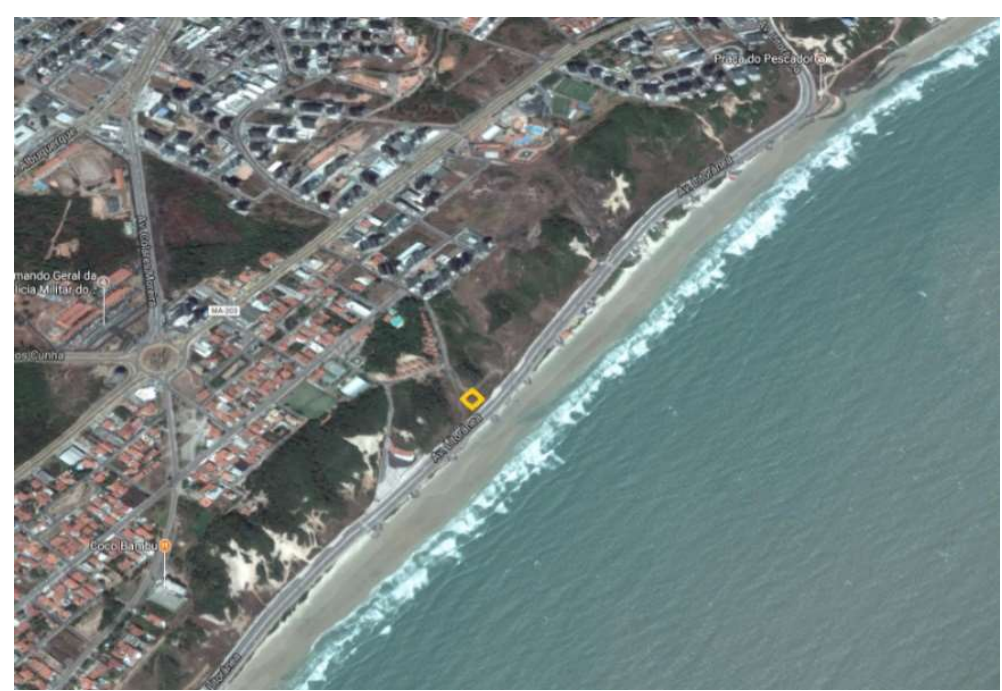

Figura 3: Localização da Voçoroca.

Através do Atlas do Maranhão podem-se obter algumas informações sobre o local a ser estudado. Percebe-se que o local está próximo da fronteira entre a Formação Itapecuru e a Cobertura Detrítica. A formação Itapecuru ocupa cerca de $50 \%$ do território estadual. Segundo Ferreira (2016), a formação Itapecuru: "É constituída por arenitos finos avermelhados e róseos cinza argilosos, geralmente com estratificação horizontal". Ainda observando o Atlas do Maranhão (GEPLAN, 2002) verifica-se que o solo é de Areia Quartzosas Marinhas e Dunas.

\section{RESULTADOS}

A partir do programa de ensaios pré-definido, foram obtidos os parâmetros de caracterização geotécnica básica do solo, os quais serão apresentados a seguir.

\section{Limites de Plasticidade e de Liquidez:}

Primeiramente, procurou-se determinar os limites de consistência para os três solos estudados (Tabela 2). Ressalta-se que para a amostra do corpo da voçoroca não foi possível formar cilindro conforme estabelecido na norma para definição do limite de plasticidade, mesmo adicionando-se água gradativamente. Já para as demais amostras, o procedimento de norma foi possível, determinando-se então os limites de plasticidade de cada solo. Para as três amostras, foram determinados os limites de liquidez, de acordo com o procedimento estabelecido em norma.

Tabela 2: Limite de Plasticidade da amostra 1,5m da cabeceira.

\begin{tabular}{|l|l|l|}
\hline Amostra & Limite de Plasticidade & Limite de Liquidez \\
\hline Corpo da voçoroca & NP & $12 \%$ \\
\hline $1,5 m$ & $9,4 \%$ & $13,1 \%$ \\
\hline Cabeceira & $10 \%$ & $12,6 \%$ \\
\hline
\end{tabular}

\section{Granulometria}

Para a realização do ensaio de granulometria do corpo da voçoroca utilizou-se $341,1 \mathrm{~g}$ e obteve-se a curva granulométrica da figura 4. 


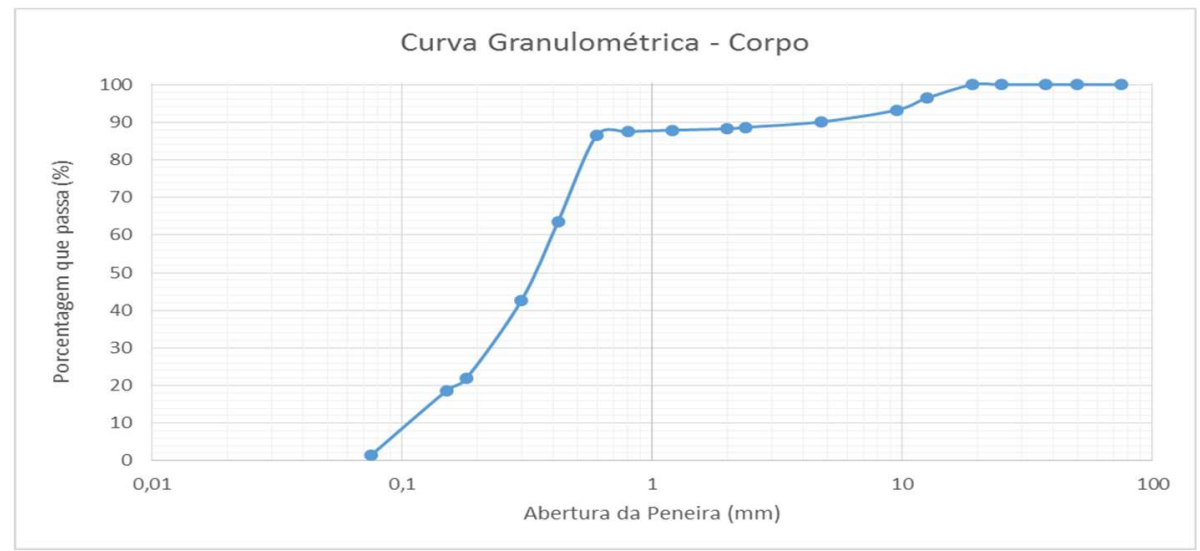

Figura 4: Curva Granulométrica do corpo da voçoroca.

Como a porcentagem de grãos que passa da peneira \#200 era inferior a 5\%, não foi necessária a realização da sedimentação, pois a fração de grãos finos não influenciará comportamento do solo. Para a amostra a 1,5m da Cabeceira utilizou-se $822,8 \mathrm{~g}$ e obteve-se a curva granulométrica da figura 5 .

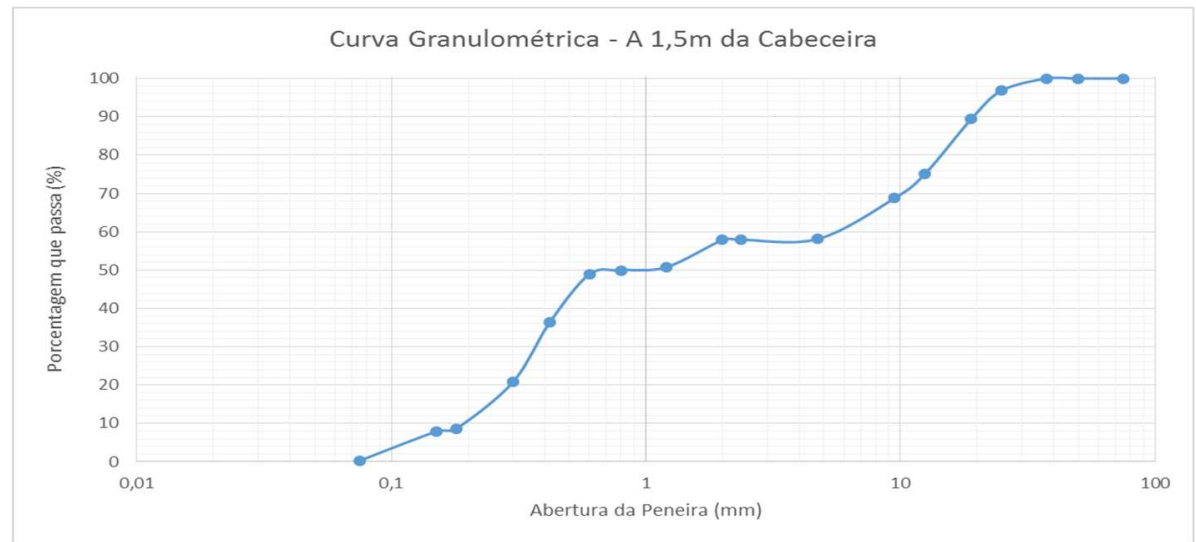

Figura 5: Curva Granulométrica a 1,5m da Cabeceira.

Novamente a porcentagem de grãos que passa da peneira \#200 foi inferior a 5\%, razão pela qual não foi realizada a sedimentação. Para a amostra da cabeceira utilizou-se 204,3g e obteve-se a curva granulométrica da figura 6 .

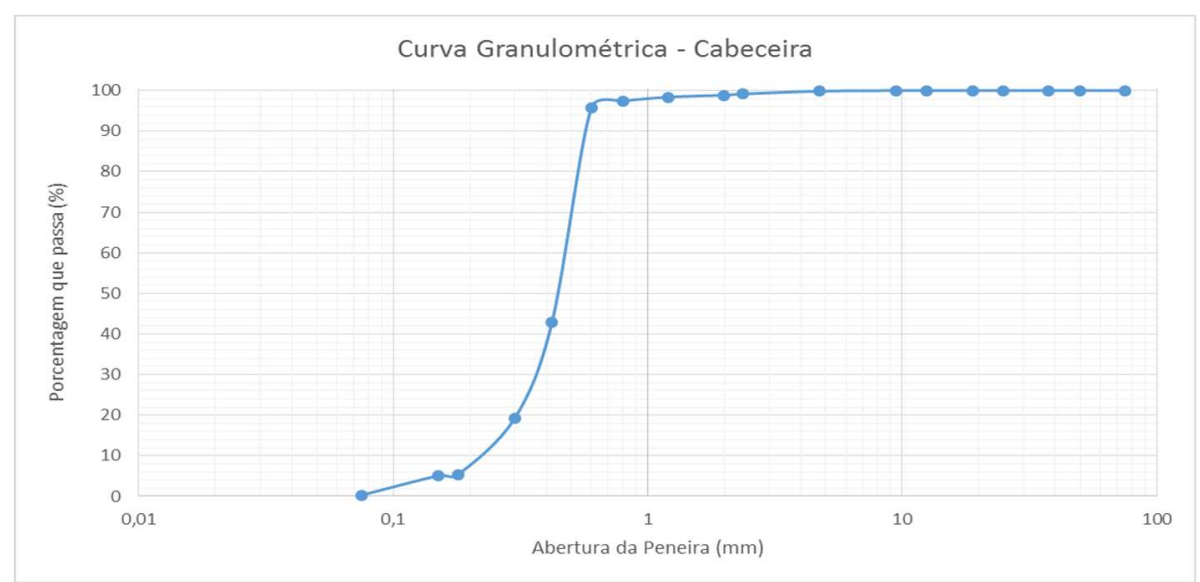

Figura 6: Curva Granulométrica da cabeceira.

Também para esse solo a porcentagem de grãos que passa da peneira \#200 mostrou-se abaixo de $5 \%$, não sendo, então, realizada etapa de sedimentação. A partir das curvas granulométricas traçadas, pôde- 
se obter parâmetros dos solos, tais como coeficiente de uniformidade, coeficiente de curvatura e percentuais de cada fração (Tabela 3). Conforme os parâmetros da SUCS/ASTM, os três solos são classificados como areia mal graduada (SP) passando a serem denominados, a partir daqui, como SP1 (corpo da voçoroca), SP2 (1,5m) e SP3 (cabeceira).

Tabela 3: Parâmetros do solo.

\begin{tabular}{|l|l|l|l|l|l|l|l|l|l|l|}
\hline & D10 $(\mathrm{mm})$ & D30 $(\mathrm{mm})$ & D60 $(\mathrm{mm})$ & Cu & Cc & \% passa \#4 & \% passa \#200 & \% Silte + Argila & \% Areia & $\begin{array}{l}\text { \% } \\
\text { Pedregulho }\end{array}$ \\
\hline Corpo & 0,11 & 0,23 & 0,4 & 3,64 & 1,2 & 90,1 & 1,47 & 1,47 & 86,80 & $11,73 \%$ \\
\hline $1,5 \mathrm{~m}$ & 0,19 & 0,37 & 5,6 & 29,47 & 0,13 & 58,1 & 0,24 & 0,24 & 57,61 & $42,15 \%$ \\
\hline Cabeceira & 0,23 & 0,37 & 0,47 & 2,04 & 1,27 & 99 & 0,29 & 0,29 & 98,58 & $1,13 \%$ \\
\hline
\end{tabular}

\section{DISCUSSÃO}

Com base nos resultados de laboratório, pode-se analisar se os indicadores de erodibilidade apresentados anteriormente fornecem resultados compatíveis com as ocorrências verificadas em campo, ou seja, se indicariam a alta erodibilidade dos solos coletados na área teste. A amostra de solo do corpo da voçoroca será chamada de SP no 1; a 1,5m da Cabeceira, de SP no 2; e a amostra da cabeceira, de SP n으 3.

\section{Araújo (2000)}

O solo SP no 1 contém cerca de 1,47\% de silte e argila, 11,73\% de pedregulho e $86,80 \%$ de areia. 0 solo SP no 2 contém cerca de $0,24 \%$ de silte e argila, 42,15\% de pedregulho e 57,61\% de areia. O solo SP no 3 contém cerca de $0,29 \%$ de silte e argila, 1,13\% de pedregulho e 98,58\% de areia. No triângulo textural, todos os solos se situam muito próximos da extremidade esquerda inferior (com pontos plotados praticamente sobrepostos), apresentando alto potencial erodível (Figura 7).

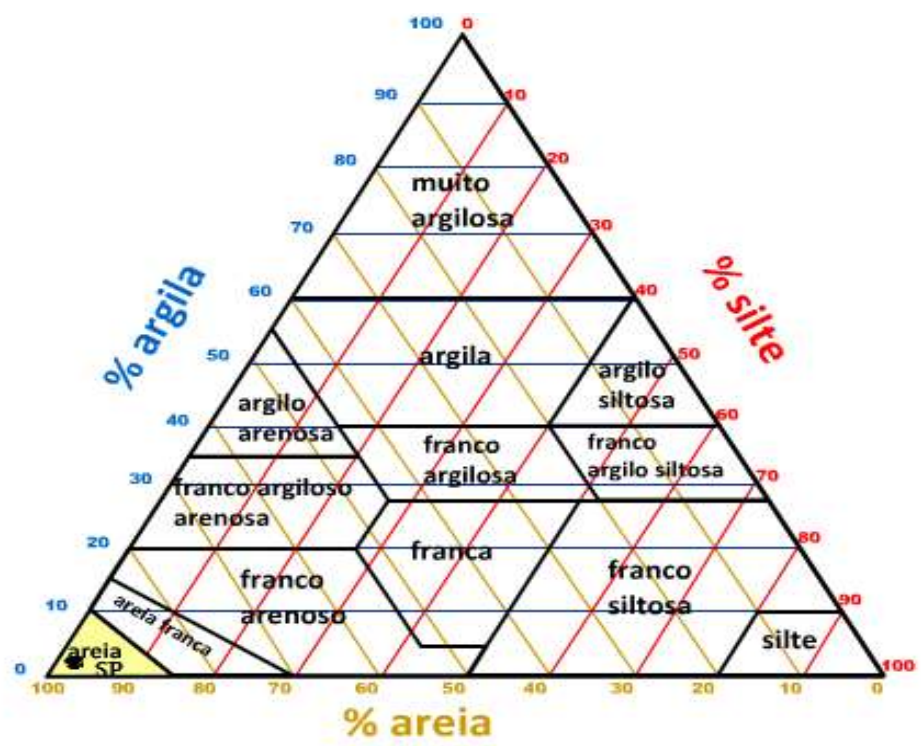

Figura 7: Quoos gerador de triangulo textural. 


\section{Mannigel et al (2002)}

Uma vez que os solos estudados apresentavam valores de silte e argila tão reduzidos que não foram realizadas etapas de sedimentação na determinação da granulometria, todos os solos os resultados indicavam apenas o percentual correspondente à soma daquelas duas frações (silte+argila). Assim, para o cálculo do K, parâmetro a ser analisado, considerou-se a condição mais favorável, ou seja, que pudesse resultar em um menor valor para tal coeficiente. Tal condição se daria supondo-se a porcentagem de silte como nula, e de argila igual ao valor silte+argila. O solo SP no 1 contém cerca de 1,48\% de silte+argila e $86,53 \%$ de areia. Neste caso, obtém-se $\mathrm{K}=0,58$ t.ha.h/ha.MJ.mm. De acordo com a classificação sugerida pelos autores da proposta, tal resultado indica trata-se de solo com alta erodibilidade. O solo SP no 2 contém cerca de $0,24 \%$ de silte+argila, resultando num $\mathrm{K}=2,41$ t.ha.h/ha.MJ.mm, apontando alta erodibilidade, para o solo. O solo SP no 3 contém cerca de $0,30 \%$ de silte+argila. Nesse caso, K=3,28 t.ha.h/ha.MJ.mm, também sendo considerado de alta erodibilidade.

\section{Santos (1953); Santos et al. (1967)}

Conforme visto, tais propostas se baseiam na porcentagem passante na peneira \#40 e no valor do parâmetro ' $a$ '. Em relação ao primeiro desses critérios, para o Solo SP no 1 obteve-se que 63,65\% dos seus grãos passam pela peneira \#40, o que leva o solo a ser classificado como de comportamento bom ou regular. Já para o Solo SP no 2, a quantidade passante na \#40 foi de 36,46\%. De acordo com os critérios da proposta, o material é classificado como 'não possui comportamento bom ou regular'. Para o Solo SP no 3, a quantidade passante foi de $42,78 \%$, o que também conduz a uma classificação de que o solo 'não possui comportamento bom ou regular'. Já em relação ao segundo critério, baseado no parâmetro 'a', a partir do gráfico, temos que para o Solo SP $n=1$ ' $a=0,54$ '. Portanto, este solo é classificado como de comportamento bom ou regular. Para o Solo SP no 2 obtém-se a=0,31, logo, este solo é classificado como 'não possui comportamento bom ou regular'. Por fim, para o Solo SP no 3 o valor de a=0,53, conduzindo à classificação deste solo como de comportamento bom ou regular.

\section{Gray et al. (1989)}

Os três solos colhidos foram classificados como sand poorly graded (SP). Os solos SP não se encontram na sequência de hierarquia de erodibilidade apresentada na proposta, portanto, essa classificação não poderá ser utilizada.

\section{Santos et al. (1967)}

Para o solo SP no 1 tem-se $L P=N P ; I P=N P$. Portanto, a rigor, tal critério não poderia ser aplicado adequadamente ao solo, ou seja, não proporcionaria uma classificação para tal material. Entretanto, uma interpretação daquele critério conduz ao entendimento que os autores consideraram que solos menos plásticos seriam menos erodíveis. Nesse sentido, fazendo-se uma 'extrapolação' da proposta, pode-se 
considerar que o solo deveria ser classificado como de bom comportamento (ressaltando-se, novamente, que tal conclusão não seria rigorosamente pelos limites indicados, mas pela lógica implícita na proposta). 0 solo SP no 2 apresenta $L P=9,4 ; I P=3,7$. Dessa forma, a classificação do material é de 'comportamento bom ou regular'. Já o Solo SP no 3 tem $L P=10 ; I P=2,6$, sendo classificado como de comportamento bom ou regular.

\section{Meireles (1967)}

Para o solo SP no 1, o limite de liquidez é igual a 12\%, portanto, inferior a $21 \%$. A porcentagem que passa da peneira 200 é 1,47\%, inferior a 20\%. Como o valor do LP não foi determinável, conclui-se que a amostra não apresenta plasticidade, ou seja, IP=0. Dessa forma, a análise leva ao entendimento de que o solo SP no 1 se enquadraria em todos os critérios para classificação como 'fortemente erodível'.

O solo SP no 2 tem limite de liquidez de 13,13\%, IP de 3,73\% e a porcentagem que passa da peneira \#200 é de 0,24\%. Este solo também apresenta todas as características previstas por Meireles (1967) para um solo fortemente erodível, por isso, é classificado desta forma. Para o solo SP no 3, o limite de liquidez é de $10 \%$, o IP é de $2,61 \%$ e a porcentagem passante da peneira \#200 é de 0,29\%. Este solo também é classificado como fortemente erodível, de acordo com os critérios estabelecidos pelo autor da proposta.

\section{Santos et al. (2001)}

Em relação ao índice de plasticidade, o solo SP no 1 apresenta IP=NP, indicando baixa resistência à erosão. Já o Solo SP no 2 apresenta IP igual a 3,73, portanto apresenta baixa resistência a erosão. O Solo SP no 3 apresenta IP igual a 2,61, portanto também é classificado como de baixa resistência a erosão. Já em relação ao Coeficiente de Uniformidade, o Solo SP no 1 apresenta Cu igual a 3,64, o que indica que este solo possui baixa resistência à erosão. $\mathrm{O}$ solo a $1,5 \mathrm{~m}$ da cabeceira tem $\mathrm{Cu}$ igual 29,47 , sendo classificado como de alta resistência à erosão. O Solo SP no 3 apresenta $\mathrm{Cu}$ igual a 2,04, portanto é classificado como de baixa resistência à erosão. A fim de melhor visualização geral dos índices analisados e as classificações de erodibilidade obtidas em cada um, a tabela 4 apresenta um quadro resumo.

Tabela 4: Quadro resumo.

\begin{tabular}{|c|c|c|c|c|}
\hline \multicolumn{5}{|c|}{ ANÁLISE DAS PROPOSTAS - Quadro Resumo } \\
\hline Autor & Parâmetro & Solo SP - 1 & Solo SP - 2 & Solo SP - 3 \\
\hline Araújo (2000) & Triângulo Textural & Solo muito erodível & Solo muito erodível & Solo muito erodível \\
\hline $\begin{array}{l}\text { Mannigel et al. } \\
(2002)\end{array}$ & $\begin{array}{lr}\text { Equação de } \\
\text { Bouyoucos (1935) }\end{array}$ & Alta erodibilidade & Alta erodibilidade & Alta erodibilidade \\
\hline \multirow[t]{2}{*}{$\begin{array}{l}\text { Santos (1953); } \\
\text { Santos et al. (1967) }\end{array}$} & $\begin{array}{l}49 \% \leq \% \text { que passa } \\
\# 40 \leq 96 \%\end{array}$ & $\begin{array}{l}\text { Possui comportamento } \\
\text { bom ou regular }\end{array}$ & $\begin{array}{lr}\text { Não } & \text { possui } \\
\text { comportamento bom ou } \\
\text { regular }\end{array}$ & $\begin{array}{lr}\text { Não } & \text { possui } \\
\text { comportamento bom ou } \\
\text { regular }\end{array}$ \\
\hline & a & $\begin{array}{l}\text { Possui comportamento } \\
\text { bom ou regular }\end{array}$ & $\begin{array}{l}\text { Não } \\
\text { comportamento bom ou } \\
\text { regular }\end{array}$ & $\begin{array}{l}\text { Possui comportamento } \\
\text { bom ou regular }\end{array}$ \\
\hline Gray et al. (1989) & (SUCS/ ASTM) & --- & --- & --- \\
\hline Santos et al. (1967) & LL, LP e IP & $\begin{array}{l}\text { Solo de comportamento } \\
\text { bom ou regular }\end{array}$ & $\begin{array}{l}\text { Solo de comportamento } \\
\text { bom ou regular }\end{array}$ & $\begin{array}{l}\text { Solo de comportamento } \\
\text { bom ou regular }\end{array}$ \\
\hline Meireles (1966) & $\begin{array}{l}\text { LL, IP e \% que } \\
\text { passa na } \# 200\end{array}$ & Solo fortemente erodível & Solo fortemente erodível & Solo fortemente erodível \\
\hline \multirow[t]{2}{*}{ Santos et al. (2001) } & IP & Baixa resistência a erosão & Baixa resistência a erosão & Baixa resistência a erosão \\
\hline & $\mathrm{Cu}$ & Baixa resistência a erosão & Alta resistência a erosão & Baixa resistência a erosão \\
\hline
\end{tabular}




\section{CONCLUSÕES}

O estudo coletou amostras com intuito de analisar a eficiência dos métodos de avaliação de erodibilidade propostos por pesquisadores. Os três solos SP estudados são potencialmente erodíveis, conforme se comprova pelo comportamento de campo, uma vez que foram coletados de uma voçoroca. Após análise, conclui-se que: O método de Araújo (2000), através do triangulo textural, teve um ótimo desempenho, onde as três amostras foram classificadas como de alta erodibilidade. Da mesma forma, Mannigel et al. (2002) também previu com precisão o comportamento das três amostras. As propostas de Santos (1953) e Santos et al. (1967) baseadas na porcentegem passante na peneira \#40 e no valor de 'a' previram corretamente o comportamento de dois dos três solos por meio do primeiro parâmetro analisado (porcentagem passante da peneira no 40), e de um dos três solos através do segundo parâmetro (valor de a). Não foi possível analisar as amostras pelo critério de Gray et al. (1989) pela limitação dos tipos de solo presentes na hierarquia proposta, a qual não inclui solos designados SP pela classificação SUCS.

O critério de Santos et al. (1967) para classificar os potenciais erodíveis por meio do LL, LP e IP geraram três previsões incorretas para os solos estudados, classificando os três solos como de comportamento bom ou regular. Ressalta-se que, a rigor, um dos solos teve LP indeterminado, gerando uma dificuldade de aplicação do critério. Entretanto, para esse material, uma 'extrapolação' da proposta (interpretando-se a lógica implícita nela) levaria à conclusão apontada acima, ou seja, de que o solo tenderia a ter bom comportamento, o que representaria uma previsão incoerente com o observado em campo.

Meireles (1967) propôs critérios de avaliação da erodibilidade com base no LL, IP e porcentagem passante da peneira no 200, prevendo corretamente os três solos estudados. Santos et al. (2001) sugere dois parâmetros: o índice de plasticidade e o coeficiente de uniformidade. $O$ índice de plasticidade proporcionou previsões corretas para os três solos. Já o coeficiente de uniformidade previu adequadamente o comportamento de apenas dois dos três solos estudados. Podem-se destacar, positivamente, as propostas de Araújo (2000), Mannigel et al. (2002) e Meirele (1967), que forneceram para as três solos previsões coerentes com as observações de seus comportamentos em campo. As propostas de Santos (1953), Santos et al. (1967) baseadas na peneira \#40 e no coeficiente 'a' forneceram classificações incorretas para SP n.1; corretas para SP n.2 e divergentes entre si para SP n.3, mostrando-se, portanto, pouco precisa.

De maneira semelhante, Santos et al. (2001) também se baseia em dois parâmetros, e gerou análises corretas para SP n.1 e SP n.3, porém conduziu a conclusões divergentes entre si para SP n.2, o que demonstra sua imprecisão. Por fim, os métodos com pior desempenho foram a proposta de Santos e al. (1967) baseada em LL e IP, a qual forneceu previsões incorretas para todos os solos, e a hierarquia de Gray et al. (1989), que nem sequer pôde ser aplicado e aos solos analisados. Conclui-se, então, que os processos erosivos são extremamente complexos, sendo necessário o estudo da atuação de diversos fatores de forma aprofundada. Pelos resultados obtidos, os métodos de previsão de erodibilidade analisados, de modo geral, não devem ser tomados isoladamente como fator decisivo em análises de risco, mas sempre de maneira conjunta a outros aspectos, tais como topografia, clima, pluviosidade e cobertura vegetal da área. 


\section{REFERÊNCIAS}

ABNT. Associação Brasileira de Normas Técnicas. NBR 6502: Rochas e solos. Rio de Janeiro, 1995.

ABNT. Associação Brasileira de Normas Técnicas. NBR 6457: Amostras de solo: Preparação para ensaios de compactação e ensaios de caracterização. Rio de Janeiro, 2016a.

ABNT. Associação Brasileira de Normas Técnicas. NBR 6459: Solo: Determinação do limite de liquidez. Rio de Janeiro, 2016b.

ABNT. Associação Brasileira de Normas Técnicas. NBR 7180: Solo: Determinação do limite de plasticidade. Rio de Janeiro, 2016c.

ABNT. Associação Brasileira de Normas Técnicas. NBR 7181: Solo: Análise granulométrica. Rio de Janeiro, 2016d.

ARAÚJO, R. C.. Estudo da erodibilidade de um solo da formação barreiras. Dissertação (Mestrado em Geotecnia) Pontifícia Universidade Católica do Rio de Janeiro, 2000.

BERTONI, J.; NETO, F. L.. Conservação do Solo. 6 Ed. São Paulo: Ícone Editora, 2008.

BOUYOUCOS, G. W.. The clay ratio as a criterion as susceptibility of soils to erosion. J. Amer. Soc. Agron., Madison, Wisc., v.27, n.9, p.738-741, 1935.

FÁCIO, J. A.. Proposição de uma metodologia de estudo da erodibilidade dos solos do Distrito Federal. Dissertação (Mestrado em Geotecnia) - Universidade de Brasília, Brasília, 1991.

FONSECA, A. M. M. C. C.; FERREIRA, C. S. M.. Metodologia para Determinação de um Índice de Erodibilidade de Solos. In: SIMPÓSIO BRASILEIRO DE SOLOS TROPICAIS EM ENGENHARIA. Anais. Rio de Janeiro, 1981.

GEPLAN. Atlas do Maranhão: Gerência de Planejamento e Desenvolvimento Econômico. Laboratório de Geoprocessamento - UEMA, São Luís: GEPLAN, 2002.
GRAY, D. H.; LEISER, A. T.. Biotechnical Slope Protection and Erosion Control. Malabar: Kriege Publishing Company, 1989.

GUERRA, A. J. T.. Geomorfologia Urbana. Rio de Janeiro: Bertrand Brasil, 2011.

LIMA, M. C.. Contribuição ao estudo do processo evolutivo de boçorocas na área urbana de Manaus. Dissertação (Mestrado em Geotecnia) - Universidade de Brasília, Brasília, 1999.

MANNIGEL, A. R.; CARVALHO, M. P.; MORETI, D.; MEDEIROS, L. R.. Fator erodibilidade e tolerância de perda dos solos do Estado de São Paulo. Acta Scientiarum., Maringá, v.24, n.5, p.1335-1340, 2002.

MEIRELES, J. M. F.. Erosão de taludes de estradas. In: SEGUNDA JORNADA LUSO-BRASILEIRA DE ENGENHARIA CIVIL. Anais. Rio de Janeiro, 1967.

SANTOS, C. A.; SOBREIRA, F. G.; COELHO NETO, A. L.. Comportamento hidrológico superficial, subsuperficial e a erodibilidade dos solos da região de Santo Antônio do Leite, distrito de Ouro Preto - Minas Gerais. Dissertação (Mestrado em Geologia) - Universidade Federal de Ouro Preto, Ouro Preto, 2001.

SANTOS, M. P. P.; CASTRO, E.. Estudo sobre erosão em taludes de estradas. In: JORNAL LUSO BRASILEIRO ENGENHARIA CIVIL, 2. Anais. Rio de Janeiro, 1967.

SANTOS, M. P. P.. A new soil constant and its applications: Proceedings of the Third International Conference on Soil Mechanics and Foundation Engineering. Zurique, 1953.

SANTOS, R. M. M.. Caracterização geotécnica e análise do processo evolutivo das erosões no município de Goiânia. Dissertação (Mestrado em Geotecnia) - Universidade de Brasília, Brasília, 1997.

A CBPC - Companhia Brasileira de Produção Científica (CNPJ: 11.221.422/0001-03) detém os direitos materiais desta publicação. Os direitos referem-se à publicação do trabalho em qualquer parte do mundo, incluindo os direitos às renovações, expansões e disseminações da contribuição, bem como outros direitos subsidiários. Todos os trabalhos publicados eletronicamente poderão posteriormente ser publicados em coletâneas impressas sob coordenação da Sustenere Publishing, da Companhia Brasileira de Produção Científica e seus parceiros autorizados. Os (as) autores (as) preservam os direitos autorais, mas não têm permissão para a publicação da contribuição em outro meio, impresso ou digital, em português ou em tradução. 